\title{
Induction of Tolerance to Clopidogrel in a Patient with Ischemic Cardiopathy
}

\author{
David El-Qutob*, Gemma Mencia and Maria Jose Bosch
}

Hospital La Plana, Vila-Real, Castellón, Spain

\begin{abstract}
Patients with acute coronary syndrome (ACS) that are admitted in the emergency room are treated with AAS and a loading dose of clopidogrel $(300-600 \mathrm{mg})$ unless contraindicated. A 47 year old male was admitted in the cardiology ward with the diagnosis of ACS. He was revascularized with two drug eluting stents. A loading dose of 300 $\mathrm{mg}$ of clopidogrel was used and a 12 months period with dual antiplatelet therapy was recommended (AAS $100 \mathrm{mg}$ plus clopidogrel $75 \mathrm{mg}$ per day). After seven days taking clopidogrel and AAS, the patient presented non-immediate erythematous, pruritic, maculopapular rash. He tolerated AAS after skin reaction. The patient was referred to our department by the cardiology service to perform an induction of tolerance to clopidogrel. There are several, outpatient and inpatient, protocols of desensitization to clopidogrel usually in one day, all of them with good results. To allow hypersensitivity symptoms to resolve before performing desensitization, these protocols require a drug washout period during which time patients are at risk for stent thrombosis while clopidogrel is withheld. We present a method for induction tolerance in a patient with probably hypersensitivity to clopidogrel who has discontinued the medication The induction of tolerance to clopidogrel has allowed the patient to continue taking this medication necessary for his health in a quickly and safely way.
\end{abstract}

Keywords: Clopidogrel; Hypersensitivity; Allergy; Desensitization; Tolerance

\section{Introduction}

The prodrug thienopyridine known as clopidogrel is actively transformed into a molecule that binds irreversibly to the P2Y12 receptor, antagonizing ADP signalling and therefore platelet activation. Patients with acute coronary syndrome (ACS) that are admitted in the emergency room are treated with AAS and a loading dose of clopidogrel (300-600 mg) unless contraindicated. When a revascularization with a stent is performed it is mandatory to treat the patient one month with two antiplatelets if it is a conventional stent and at least 12 months if it is a drug eluting stent. Percutaneous coronary intervention (PCI) is the preferred treatment of acute myocardial infart in ST-segment elevation acute coronary syndrome [1]. More than 2 million of procedures are performed annually worldwide. There is $1 \%$ incidence of stent thrombosis after PCI

\section{Clinical Summary}

A 47 year old male who is admitted in the emergency room of our hospital with chest pain. He referred chest oppression without any other accompanying symptoms at rest. In the ECG without pain the only findings were T negative waves in lead III and AVF and in his blood test there was no elevation of cardiac biomarkers. He was admitted in the cardiology ward with the diagnosis of ACS without ST segment elevation (unstable angina). In the echocardiogram the left ejection fraction was preserved and there were no segments with hypochinesia. He underwent a cardiac catheterism the next day and a significant lesion was seen in the right coronary artery. He was revascularized with two drug eluting stents. A loading dose of $300 \mathrm{mg}$ of clopidogrel was used and a 12 months period with dual antiplatelet therapy was recommended (AAS $100 \mathrm{mg}$ plus clopidogrel $75 \mathrm{mg}$ per day). The day after revascularization he started treatment with Duocover ${ }^{\circledR}$, and was sent home also with ranitidine $150 \mathrm{mg}$, bisoprolol $2.5 \mathrm{mg}$ and atorvastatin $40 \mathrm{mg}$.

After seven days taking Duocover ${ }^{\circledR}$, the patient presented nonimmediate erythematous, pruritic, maculopapular rash. He was admitted to the emergency room of our hospital and clopidogrel was discontinued. Administration of parenteral corticosteroids and antihistamines resolved the exanthema in hours. He continued treatment with the other drugs (raniditina, bisoprolol 2,5 $y$ atosvastatina $40 \mathrm{mg}$ ) and AAS $100 \mathrm{mg}$ daily for one day and the next day the dose was augmented to $300 \mathrm{mg}$ of AAS. The patient was referred to our department by the cardiology service to perform an induction of tolerance to Duocover ${ }^{\circledR}$.

\section{Pathological Findings}

There was not history of atopy. Patient provided informed verbal and written consent prior to the procedure. After one intramuscular dose of $60 \mathrm{mg}$ of 6-metilprednisolone, the patient received a tablet of $75 \mathrm{mg}$ of clopidogrel and was monitored during 6 hours at hospital. $\mathrm{He}$ tolerated Duocover ${ }^{\circledR}$ and subsequently daily dosage. The patient has not recurrance of exanthema during a follow-up of one month (Table 1).

\section{Discussion}

Pruritic rash affects up to $6 \%$ of patients taking clopidogrel and results in premature drug discontinuation in $1.5 \%$ of patients. In a recent review of 76 subjects, $27 \%$ of patients with a hypersensitive or

\begin{tabular}{|l|l|}
\hline Days $1-6$ & Duocover $^{\circledR}$ \\
\hline $7^{\text {th }}$ day & Duocover $^{\circledR}$-Rash \\
\hline $8^{\text {th }}$ día & AAS $100 \mathrm{mg}$ \\
\hline $9^{\text {th }}$ día & AAS $300 \mathrm{mg}$ \\
\hline $10^{\text {th }}$ día & Induction of tolerance to Duocover \\
\hline
\end{tabular}

Table 1: Chronology of treatment.

*Corresponding author: David El-Qutob, Hospital La Plana, Unit of Allergy, Carretera Vila-Real-Burriana, km 0.5 Vila-Real, Castellón 12540, Spain, E-mail: elqutob@comv.es

Received June 08, 2013; Accepted July 22, 2013; Published July 28, 2013

Citation: El-Qutob D, Mencia G, Bosch MJ (2013) Induction of Tolerance to Clopidogrel in a Patient with Ischemic Cardiopathy. J Allergy Ther 4: 144. doi:10.4172/2155-6121.1000144

Copyright: (c) 2013 El-Qutob D, et al. This is an open-access article distributed under the terms of the Creative Commons Attribution License, which permits unrestricted use, distribution, and reproduction in any medium, provided the original author and source are credited. 
<smiles>[CH][C@H](c1ccccc1Cl)N1CCc2sccc2C1</smiles>

Clopidogrel<smiles>C[C@@H](C(=O)O)c1ccccc1Cl</smiles>

Figure 1: Ticlopidine and clopidogrel.

hematologic adverse reaction to clopidogrel also experienced a similar reaction to ticlopidine [2] (Figure 1). Based in this information, we choice to perform an induction to clopidogrel and not challenging with ticlopidine in this patient.

Ideally, the term desensitization should be reserved for those reactions that have an IgE-mediated mechanism. However, the term has also been used to describe a state of unresponsiveness to a drug that is accomplished by repeated and increasing exposure to that agent [3]. This may include delayed, not IgE-mediated, reactions as in our patient.

There are several, outpatient and inpatient, protocols of desensitization to clopidogrel usually in one day [4-12], all of them with good results. To allow hypersensitivity symptoms to resolve before performing desensitization, these protocols require a drug washout period during which time patients are at risk for stent thrombosis while clopidogrel is withheld. Premature discontinuation of thienopyridine therapy is associated with 3 -fold increase in stent thrombosis [13]. Campbell et al. have published the results of the management of clopidogrel hypersensitivity without drug interruption. Treatment of clopidogrel hypersensitivity was successful in 22 of 25 patients (88\%) [14]. Cheema et al. [15] studied 84 patients for suspected clopidogrel hypersensitivity but only sixty-two patients were treated with 3 -week tapering course of oral prednisone, and 59 patients reported complete resolution of clopidogrel hypersensitivity at $5 \pm 2$ days approximately as our patient. Drug allergy tests were performed after completion of prescribed clopidogrel therapy. The lesions of our patient are characteristic of non IgE-mediated reaction, as well as the timing of the reaction. Because the patient needed to continue the medication as soon as possible, it was not possible to assess clopidogrel hypersensitivity at the moment of the skin reaction. We have avoided the use of oral corticosteroids for several weeks that may produce adverse side effects.

We present a method for induction tolerance in a patient with probably hypersensitivity to clopidogrel who has discontinued the medication. The induction of tolerance to clopidogrel has allowed the patient to continue taking this medication necessary for his health in a quickly and safely way.

\section{References}

1. Smith SC Jr, Feldman TE, Hirshfeld JW Jr, Jacobs AK, Kern MJ, et al. (2006) ACC/AHA/SCAI 2005 guideline update for percutaneous coronary intervention: a report of the American College of Cardiology/American Heart Association Task Force on Practice Guidelines (ACC/AHA/SCAI Writing Committee to Update the 2001 Guidelines for Percutaneous Coronary Intervention). J Am Coll Cardiol 47: e1-e121.

2. Lokhandwala JO, Best PJ, Butterfield JH, Skelding KA, Scott T, et al. (2009) Frequency of allergic or hematologic adverse reactions to ticlopidine among patients with allergic or hematologic adverse reactions to clopidogrel. Circ Cardiovasc Interv 2: 348-351.

3. Ditto A (2002) Drug Allergy, in Patterson's Allergic Diseases, L. Grammer and P. Greenberger, Editors. Lippincott Williams \& Wilkins: Philadelphia: 333-334.

4. Sanchez-Lopez J, Muñoz-Cano R, Bartra J, Valero A, Picado C (2010) Desensitization to clopidogrel: a growing need. Allergy 65: 279-280.

5. Camara MG, Almeda FQ (2005) Clopidogrel (Plavix) desensitization: a case series. Catheter Cardiovasc Interv 65: 525-527.

6. Walker NE, Fasano MB, Horwitz PA (2006) Desensitization for the management of clopidogrel hypersensitivity: initial clinical experience. J Invasive Cardiol 18 341-344.

7. Kammer RT (2009) Successful clopidogrel desensitization after drug-eluting stent implantation. J Invasive Cardiol 21: 134-135.

8. von Tiehl KF, Price MJ, Valencia R, Ludington KJ, Teirstein PS, et al. (2007) Clopidogrel desensitization after drug-eluting stent placement. J Am Col Cardiol 50: 2039-2043

9. Fajt M, Petrov A(2010) Clopidogrel hypersensitivity: a novel multi-day outpatient oral desensitization regimen. Ann Pharmacother 44: 11-18.

10. Owen P, Garner J, Hergott L, Page RL 2nd (2008) Clopidogrel desensitization: case report and review of published protocols. Pharmacotherapy 28: 259-270.

11. Oppedijk B, Odekerken DA, van der Wildt JJ, Melissant CF (2008) Rapid ora desensitisation procedure in clopidogrel hypersensitivity. Neth Heart J 16: 21 23.

12. Lee-Wong M, Gadhvi D, Resnick D (2006) Clopidogrel desensitization. Ann Allergy Asthma Immunol 96: 756-757.

13. lakovou I, Schmidt T, Bonizzoni E, Ge L, Sangiorgi GM, et al. (2005) Incidence, predictors, and outcome of thrombosis after successful implantation of drugeluting stents. JAMA 293: 2126-2130.

14. Campbell KL, Cohn JR, Fischman DL, Walinsky P, Mallya R, et al. (2011) Management of clopidogrel hypersensitivity without drug interruption. Am J Cardiol 107: 812-816.

15. Cheema AN, Mohammad A, Hong T, Jakubovic HR, Parmar GS, et al. (2011) Characterization of clopidogrel hypersensitivity reactions and management with oral steroids without clopidogrel discontinuation. J Am Coll Cardiol 58 : $1445-1454$. 